MATEC Web of Conferences 6, 03007 (2013)

DOI: $10.1051 /$ matecconf/20130603007

(C) Owned by the authors, published by EDP Sciences, 2013

\title{
Permeability of concrete under thermal and compressive stress influence; an experimental study
}

\author{
H. Lun and R. Lackner \\ Material Technology Innsbruck (MTI), University of Innsbruck, Technikerstraße 13, \\ 6020 Innsbruck, AUSTRIA
}

\begin{abstract}
In recent years the permeability was found as one of the main parameters affecting the durability of concrete. Especially in concrete at high temperatures in case of fire loading, the interaction of thermal/mechanical loading and fluid transfer strongly influences degradation of mechanical properties within concrete and spalling of near-surface concrete layers. To understand the change in transport properties of concrete, a new experimental setup was developed, allowing us to conduct permeability tests under uniaxial compressive loading up to $20 \mathrm{MPa}$ and thermal condition up to $350^{\circ} \mathrm{C}$. Based on the obtained results, the effect of both mechanical and thermal loading on the effective transport properties is highlighted and relations to more simplified test setups, disregarding mechanical loading and/or conducting the permeability test at room temperature giving the residual permeability, are established.
\end{abstract}

\section{INTRODUCTION}

The porous system of concrete is occupied by water and gas phases. In case of temperature loading, this system changes by evaporation of water phases, on the one hand, and the development of new pore space by the opening of microcracks, on the other hand. As regards the latter, additional mechanical loading may affect the opening of microcracks showing strong interaction between thermal and mechanical loading. In addition to these microcracks, dehydration of CSH phases increases the permeability of heated concrete, which has been identified as the main parameter influencing spalling of concrete when subjected to fire loading. This effect of thermal and/or mechanical loading on the permeability has been studied in [1-3]. However, the correlation of both influences, which occur during fire exposure in real structures, lead to a further understanding of the destruction and, hence, spalling mechanisms of concrete.

\section{MATERIALS AND METHODS}

To estimate the influence of mechanical and thermal load on concrete a experimental setup was developed, which permits to investigate the change of permeability under uni-axial compressive load up to $20 \mathrm{MPa}$ and thermal condition up to $350^{\circ} \mathrm{C}$. The development of the setup was performed in 3 steps:

1. First the test-setup for permeability measurement under thermal condition was developed. In this step measurements on specimens with and without polypropylene fibres were performed to investigate their influence during the heating.

2. The next step included the implementation of a hydraulic press system. Specimen were tested with combination of thermal and mechanical load. (Fig. 1a). Measurement were performed with the same

This is an Open Access article distributed under the terms of the Creative Commons Attribution License 2.0, which permits unrestricted use, distribution, and reproduction in any medium, provided the original work is properly cited. 

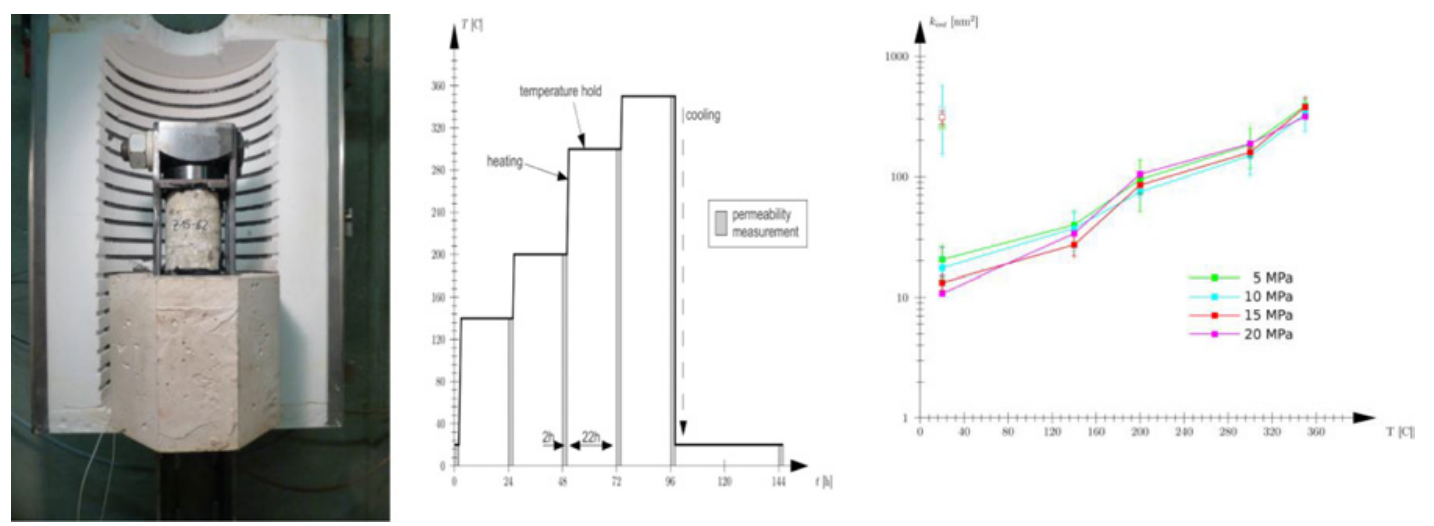

Figure 1. Test setup in the oven (left-a), heating and measurement procedure (middle-b) and experimental intrinsic permeability results (development step 2) (right-c).

heating procedure as in step one (Fig. 1b) with additional defined mechanical stress level $(5,10,15$, $20 \mathrm{MPa}$ ).

3. To further understand the influence of the combined load on the examined concrete the change of elasticity was investigated and the obtained results compared with the permeability results.

The different loading types where tested on concrete samples with the same mixture containing quartziferous aggregates. For specimens with polypropylene fibres $1.5 \mathrm{~kg} / \mathrm{m}^{3}$ were added.

\section{RESULTS AND CONCLUSIONS}

The results show a increase of permeability with increasing temperature level, especially for concrete with polypropylene fibres, where a steep increase in permeability for temperatures above the melting point of polypropylene $\left(165^{\circ} \mathrm{C}\right)$ was noticed. The compressive stress leads first $(5-10 \mathrm{MPa})$ to a reduction of the permeability. With increasing pressure concrete deforms plastically, which leads $\left(15 \mathrm{MPa} / 200^{\circ} \mathrm{C}, 20 \mathrm{MPa} / 140^{\circ} \mathrm{C}\right)$ to a increased permeability (Fig. 1c). This tendency can be explained with the occurrence of plastic deformations of concrete during thermal influence. The results show that the combination of thermal and mechanical load has a great influence especially for highly exposed structures.

\section{References}

[1] M. Choinska, A. Khelidj, G. Chatzigeorgiou, G. Pijaudier-Cabot, Effects and interactions of temperature and stress-level related damage on permeability of concrete, Cement and Concrete Research 37 (1) (2007) 79-88.

[2] A. Galek, H. Moser, T. Ring, M. Zeiml, J. Eberhardsteiner, Mechanical and transport properties of concrete at high temperatures, Applied Mechanics and Materials 24-25 (2010) 1-11.

[3] R. Haniche, G. Debicki, A. Bouamrane, E. Zeltz, Gas transfers and flow process through concrete maintained in temperature, no. 18, RILEM Publications SARL, 2011. 